\title{
A Comparative Study of Boosting in Academic Texts: A Contrastive Rhetoric
}

\author{
Oktay YAĞIZ1 \& Cuneyt DEMIR ${ }^{2}$ \\ ${ }^{1}$ English Language Teaching Department, Atatürk University, Erzurum, Turkey \\ ${ }^{2}$ English Language Teaching Department, Siirt University, Siirt, Turkey \\ Correspondence: Oktay Yağız, Atatürk Üniversitesi, Yabancı Diller Yüksekokulu, Erzurum, Turkey. Tel: \\ 90-442-231-1111 (pbx. 4700). E-mail: yoktay@atauni.edu.tr
}

Received: May 28, 2015 Accepted: June 20, 2015 Online Published: July 30, 2015

doi:10.5539/ijel.v5n4p12 URL: http://dx.doi.org/10.5539/ijel.v5n4p12

\begin{abstract}
Boosting, an authorial commitment, and hedging, a authorial mitigating, are two issues interconnected one another with a gaining importance in the last decades (for detail see Gillaerts \& Velde, 2010). However, boosting has remained as an issue needing to be studied from different aspects; for instance, cross-linguistic, cross-disciplinary, cross-cultural or comparative while hedging gains a great deal of attention from researchers. The purpose of the present study is to investigate the corpora in terms of statistical inclusion of certainty markers in the research articles written in English by Turkish, Japanese and Anglophonic authors, and then to explain the results obtained through statistical tests in the sense of linguistic and cultural factors. A corpus of total 60 research articles written by 20 Anglophonic authors, 20 Japanese authors, and 20 Turkish authors of English constituted the data for the present study. The data were scanned by researchers of the present study. Having completed the scanning, the words functioning as boosters were categorized in line with the taxonomy created for the present study. Then, the total certainty markers for each group of scholars were calculated and analyzed through ANOVA test. The test results provided whether there were any statistically significant differences among the groups in terms of including boosters in the research papers. Furthermore, the present study formed a boosting list as a result of dictionary scanning, which may be a reference for further studies, and the most and the least used boosters of authors were gathered in the tables.
\end{abstract}

Keywords: Anglophonic, assertiveness, booster, boosting, Japanese, Turkish

\section{Introduction}

Boosting, also called intensifiers or certainty markers interchangeably, is an issue studied under metadiscourse. It creates an emphatic impression in the reader, that is, an impression of certainty, conviction and assurance. In other words, boosters may be thought as metadiscoursal markers aiming to strengthen writers' claims on the issue, accordingly a heftier conviction impact on the stockholder. Along similar lines, they have a purpose of increasing the propositions, and prove the writer's engagement and commitment to his/her statements (Hyland, 1998). In brief, boosters are intensity markers that prove the author's stance on a colossal scale by narrowing discursive space.

Boosting has always been studied together with hedging, which is a de-intensifier statement and a tentative language to reduce the writer's commitment. While there exist some studies conducted only on hedging, boosting surprisingly has been avoided to be studied distinct from hedging. With an explicit parlance, it has stayed under the shadow of hedging because of co-processing. So, a study that descends into particular in order to investigate emphatic expressions would be of utmost importance to able to gain further insight into boosting. On the top of this, now that a paper is written to convert a knowledge to another or to support the idea by convincing the readers, boosting is an indispensible part in order to realize that aim for the authors. More, it is difficult to gauge the effect of a writing over the audience, but through boosting it may be possible to increase the impact level by stating the resolution.

As aforementioned, the high majority of the studies in the literature conducted the issue dichotomously; hedging and boosting which is likely to end with insufficient care in terms of boosting because it generally underestimated when studied with hedging. So, there seems a paucity of studies conducted only on boosting. 
Furthermore, the studies in the literature show that they were conducted by analysing surface linguistic features of boosters but not other factors that could be important like cross-cultural. Indeterminate knowledge on cross-cultural factors as regards boosting makes it needy to investigate the issue in-depth on whether the culture of the author, as well as surface linguistic features, has any effect on the use of intensity markers in his/her writings.

The present study aims to investigate three types of authors namely from Japan, Turkey and Anglophonic countries. Thanks to the present study, cross-cultural impacts on employing boosters and linguistic differences on the preference of boosting devices will be determined through a series of literature scanning and statistical tests. At the end, some window on boosting tendencies of Anglophonic, Japanese, and Turkish writers is going to be provided.

\subsection{Further Rationale for Research into Boosting}

Boosting may be thought as the illocutionary force of speech, so may be treated under indirect speech acts of Austin (1962) and Searle (1969), as stated by Holmes (1984, p. 347), modifying the illocutionary force of speech acts involves increasing or decreasing the strength with which the illocutionary point is presented"'. The commitment in the illocutionary force may give rise to the perlocutionary act by contributing to the effect of the discourse; that it, to have a concrete impact on the stockholder.

Another issue that needs to be investigated is the scale of boosting in academic texts. Now that commitment has a positive effect on conviction of the reader on the discussed issue of the text; the more the producer employs boosting devices in his/her texts the higher acceptability level she or he is going to reach. That straightforward logic does not make sense at all. So what we know, as stated by Hyland (1998b), is that there needs to be an equilibrium concerning the amount of use of boosting devices in academic texts. Through overusing intensity markers, it is possible to create a counter-effect with the reader and reduce the credibility of the statements because much evidence would be needed to cover too assertive or challenging stances.

A research conducted by Kaplan (1976) indicated that the use of metadiscourses, particularly intensity markers, in texts varies across one language and culture to another. That is to say, metadiscourses like hedging and boosting in a language and culture are not tantamount to the one in another language and culture. So, a study conducted among a particular culture would only provide a unique result for the context it was studied in, and would not be generalizable to other contexts; therefore metadiscoursal devices should be unravelled with a distinct research for each culture and language.

The reviewed linguistic literature shows the close relation between hedges and boosters. Many studies regard the issue bivious as hedging and boosting (for example see Hyland, 2000; Vassileva, 2001; Alward, Mooi, \& Bidin, 2012; Uysal, 2014). Furthermore, although there exist some studies only conducted on hedging (e.g. Crompton, 1997; Lewin, 2005; Nivales, 2011; Yang, 2013), it is difficult to encounter any study focusing on only boosting (for exceptions see Wee, 2004; Peacock, 2006; Dobakhti, 2013). The matter with studying hedging and boosting together is that boosting is usually underestimated because of the hefty importance paid to hedging devices. That results in parsimonious account of boosting in bilateral studies which included both hedging and boosting. Consequently, a study focusing on only boosting will be of great importance in providing some leeway data for the linguistic literature, and get kudo from those who brace for a research bond with boosting.

\section{Literature Review}

Boosters, despite paucity of studies, have been investigated by researchers through different analyses depending on myriad features of them. The linguistics literature proves that the majority of the existent studies focussed on cross-disciplinary bases of boosting devices. One example for this belongs to Peacock (2006) who had a cross comparative research of six academic disciplines. For him, Language and Linguistics had the highest proportion of boosting devices with 10.98 per 1000 words when compared to other social science disciplines. Another study (Vázquez \& Giner, 2009) aimed a similar purpose by changing the data source, and found that intensifiers are used by scholars in Biology and Mechanical Engineering well enough but not as much as in Marketing. The question of whether soft sciences or hard sciences include boosters more has allured to some scholars (Khedri, Ebrahimi, \& Heng, 2013), and their results suggested that emphatics are required in soft sciences more than in hard sciences.

Besides cross-disciplinary studies, the literature provides us with comparative studies which compared native and non-native writers of English. Vassivela (2001) found that Bulgarian English authors employ boosting devices more than native writers of English, especially in discussion parts of their writings. Accordingly, a study (Chen, 2012) conducted with Chinese English writers produced an exact similar result, and showed that native 
writers' texts included stronger assertions and more certainty markers than those of EFL Chinese university students'. In contrast to the both studies indicated above, some scholars (Yazdani, Sharifi, \& Elyassi, 2014), who investigated boosters in media articles, did not mention about any statistically significant difference between American and Persian news articles in terms of boosting frequency. Another study (Kobayashi, 2009) which aimed to detect whether Japanese EFL learners or native writers of English included boosters in their texts revealed that Japanese EFL learners were at the lack of lexical variations of boosting devices. Since meta-discourse factors like boosting embedded themselves in culture-specific situations, hence are differential issues according to cultures, they should be studied by keeping the cultural factors in the picture. That is, studies aiming the same purpose will not provide the same results in the contexts in which they are investigated. Therefore, the indeterminacy of studies as regards boosting devices can easily be understood better from the literature if examined thoroughly.

Cross-linguistic studies are existent in the literature as well. One of the earliest cross-linguistic studies (Cmejrkova, 1996) found that Czech linguist writers of English are more detached, and use more tentative language when compared to the native writers of English. Accordingly, Chinese students are claimed to be more assertive in their L1 writings than L2 English writings (Kim \& Suh, 2014). So it seems that the same author may change his/her writing style in terms of metadiscoursal devices depending on the language he or she prefers to use.

On the other hand, some researchers investigated organizational distributions of emphatics over the paper. For example, in a study (Gillaerts \& Velde, 2010) the data of which consisted of only research article abstracts showed that abstracts have more affinity with intensity markers when compared to hedging. However there are studies which suggested that discussion and conclusion parts included boosting much more when compared other parts of an article (e.g., Salek, 2014). While some studies prefered to study organizational distributions of boosting, some others prefered to study whether there could be any differences in boosting in terms of researh design of the papers. In that sense, empirical and non-empirical academic articles were gleaned and examined by $\mathrm{Hu}$ and Cao (2011). Another study (Dobakhti, 2013) divided its data not as empirical and non-empirical but as qualitative and quantitative. Furthermore, it is possible to encounter with a variety of studies conducted on boosting through different aims and data gatherings. For example, Holmes (1990) made a gender analysis in terms of using boosting while Kondowe (2014) studied only doctoral students writings', and Aull and Lancester (2014) bachelor students' writings.

As stated so far, linguistics literature conflates varied studies on boosting studies under many guises. Whilst some of them underscore the importance of cross-linguistic differences, the others point out the similarities and differences in employing boosting in the manuscripts of native English writers and non-native English writers. Moreover, there are studies aiming to detect pragmatic usage of boosters in disparate academic disciplines; to what extent they bear resemblance and at what points they differ from one another. As last, it is possible to take on studies challenging the use of emphatics in academic texts. Though there seems a spurt in the number of metadiscoursal studies which have a purpose of eliciting their pragmatic or contextual functions in academic writings, the high majority of the studies in the literature preclude, or at least overlook, the possible effect of culture in employing emphatics. While studies grapple with statistical and linguistic factor to able to reach a reasonable result, the corollary may lie under certain culture-based rationales. So, if it will not be too assertive to say, the parochial studies in the literature presage the present study to investigate the issue from a different perspective that other studies failed to notice.

\subsection{Research Aim and Questions}

The purpose of the present study is two-folded. The first is to investigate the corpora consisting of 60 research papers on ELT in terms of statistical including of certainty markers in the English writings of Turkish, Japanese and Anglophonic writers. The second is to explain the results obtained through statistical tests in the sense of cultural factors. Specifically, research questions are as follows:

1) What are the most common certainty markers that the three groups of writers, namely Turkish, Japanese, and Anglophonic, employed in their writings?

2) Are there any statistically significant differences between Anglophonic, Japanese and Turkish authors in terms of booster productivity and booster variety?

3) How can the results be explained by taking the cultural factors into consideration? 


\section{Methodology}

\subsection{Corpora}

A corpus of total 60 research articles (RAs) written by 20 Anglophonic authors, 20 Japanese authors, and 20 Turkish authors of English constituted the data for the present study. Three groups of writers were chosen for three reasons: (i) there are very few studies conducted to investigate boosting devices employed in RAs particularly of Japanese and Turkish writers of English; (ii) there seem no studies investigating these particular three groups of writers who bear different cultural background; (iii) Japanese represent for far-east communities while Anglophonic authors represent for west communities. Turkey's geographical position gives it to be a west community as well as an east community, which may be considered as a culture bridge between east and west. Therefore, Turkey is a country carrying the characteristics of west as well as east. The RAs were gleaned randomly from leading journals on ELT. Again, only RAs written on ELT subjects were compiled for two reasons: (i) hedging and other features of opinion positioning, like boosting, are said to differ across disciplines (Hyland, 2005). (ii) non-native writers of other disciplines, namely Japanese and Turkish, could get professional English help while writing their articles, which might debase both reliability and validity of the research aim. RAs published after 2005 were gathered in order to see synchronical variations on the use of boosting. The corpora are consisted of 260901 words in total. The figure covers only the main parts of the articles, and excludes titles, abstracts, acknowledgements, references and appendices. It was tried to compile the corpora from equi-length RAs so as not to lead any reliability concern (see Table 1). Verification about author nativeness was not ensured by contacting them. Authors' status of nationality was presumed based on their names or nationalities. In RAs where more than one scholar is involved, the corresponding author or the first author in the affiliation was regarded as the writer of RA, hence the nationality of the first or corresponding author determined the status of nativeness of all others.

Table 1. Vocabulary numbers for each author type

\begin{tabular}{lllll}
\hline & Anglophonic & Japanese & Turkish & Total \\
\hline Tokens & 90152 & 82280 & 88469 & 260901 \\
Words & 6807 & 7401 & 5937 & 20145 \\
\hline
\end{tabular}

As seen from the table one, Japanese writers are at the first rank in using vocabulary diversity, followed by Anglophonic writers. As last, it is seen that Turkish writers are behind of both Japanese and Anglophonic writers in terms of word number.

\subsection{Data Analysis and Procedure}

It is possible to categorize the boosting devices into different categories. That has given rise to diverse taxonomies for categorization of boosters. The present study will examine the corpora based on four main categories as follows:

1. Modal auxiliaries: must, will...

2. Epistemic lexical verbs: demonstrate, show, find...

3. Epistemic adjectives: rigorous, superior, undeniable...

4. Epistemic adverbs: actually, always, clearly...

There are different software PC-based programs which calculate the number of words in a .txt files. Through one of the known concordance software programs, the total word count was calculated and given in the table 1 . However it is absolutely necessary to make a scanning of the corpora by the researchers in order to detect the semantic case of the words in that a concordance program only gives the statistical information about the words but not semantic or pragmatic. Further to say, a modal auxiliary word 'will' would not function as a boosting device in every sentence it was used. For example, in a sentence 'Now, we will interpret the results', 'will' does not have a function of certainty marker, but a 'tense case'. More, it is rather possible and common to see an epistemic lexical verb functioning not as a booster for conviction, strong commitment or high value, but a lexicographic meaning concentrated only on the action. For instance, the case of 'find' in 'Our results find the best solution for the matter' can be considered as a intensity markers while in the sentence 'Our results find two ways of getting rid of...' cannot be. So, in order to ensure the boosting function of the words, a semantic and pragmatic scanning of the papers is required to find out whether the words in the text have a role of boosting or not. Another important thing with the data analysis is that only boosters the writers of the papers used were 
included in the analysis. For example, the references that the writers did as in "one longitudinal study found that vocabulary is..." were not considered as the discoursal markers of the writers own, so excluded from the data. Before categorization of the boosters, an advance dictionary was scanned and a boosting list was made (see Appendix A).

Having completed the scanning, the words functioning as boosters were categorized in line with the taxonomy stated above. Second, the total certainty markers for each group of scholars were calculated and analyzed through SPSS program by employing ANOVA test. The test results provided whether there were any statistically significant differences among the groups in terms of including boosters in the published papers. Then, how many boosters for each category, lexical booster variety, the authors used was calculated. As last, it was aimed to provide some explanations through the literature in order to elicit the possible differences among the groups.

\subsection{Inter-Rater and Intra-Rater Reliability}

In order to validate the analysis, both inter- and intra-rater agreement were tested. Two raters consisted of the researchers of the present study worked as the raters in evaluating the corpora. The first rater has a $\mathrm{PhD}$ degree in ELT, and has been on duty for over 30 years. As regards the second rater, he has an MA degree on ELT, and has been an instructor on duty at a university for 6 years. The boosting list was given to both raters, and required them to categorize the boosters in the corpora accordingly. To maintain consistency in scoring and to minimize any bias a rater could develop, each rater independently categorized and checked the entire count of boosting devices tied up to a certain evaluation criteria separated into four as 'modal auxiliary, epistemic lexical verb, epistemic adjectives \& adverbs, and miscellaneous' (given in Appendix A). Inter-rater agreement measured through Cohen's kappa in terms of how the corpora were examined; and the result was .82, which equals to not perfect agreement but substantial. So, it can be said that there existed a correlation or homogeneity between the raters in terms of categorizing the boosters. The intra-rater analysis was made by re-checking the results in detail (every certainty makers which were detected in the corpora) ten weeks after the initial analysis. The intra-rater test yielded a statistical result of .92 percent.

\section{Results}

\subsection{Overall Distribution}

Having scanned the corpora, the researcher noted down all the boosters used in the academic text of three groups of authors (see Appendices B, C, and D). According to the analysis results given in the figure 1;

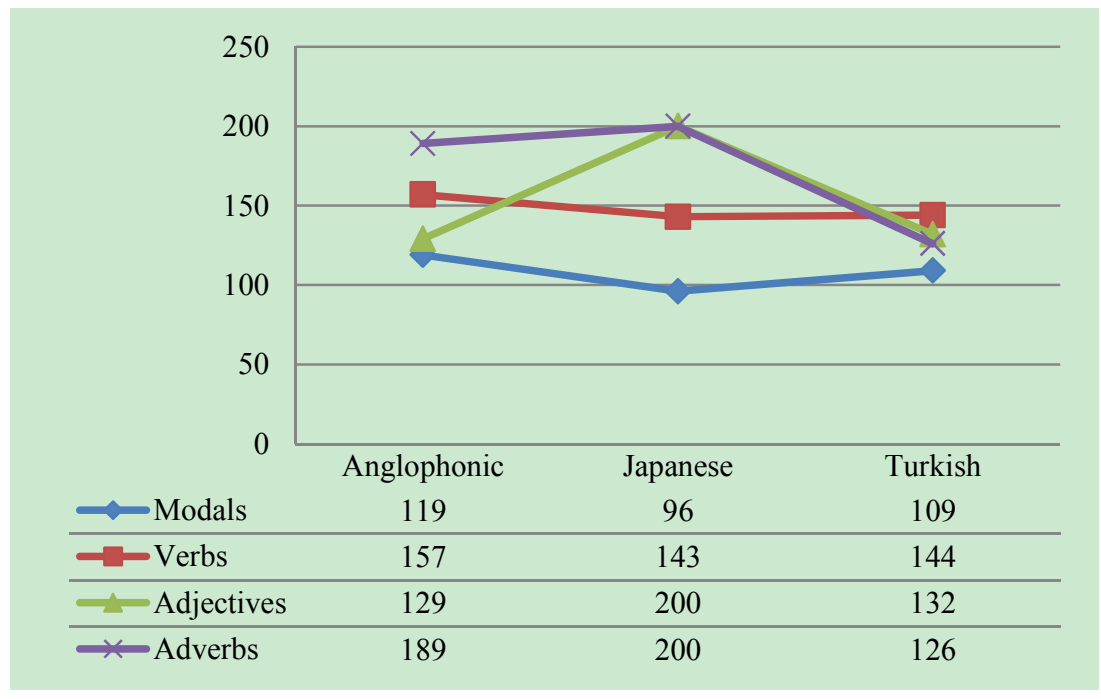

Figure 1. Distribution of boosters across categorizations and authors

Anglophonic authors used adverbial boosters at the highest scale while Turkish authors at the least. As regards adjectival boosting devices, Japanese authors get the frontmost while Anglophonic authors the backmost. Verbal boosters were employed 157 times by Anglophonic authors whereas Japanese and Turkish authors employed verbal boosters almost at the same number; 143, 144 respectively. Epistemic modal boosting devices accounted 
for the smallest percentage of all boosting types. As seen in the figure 1, all author groups used modal boosters least.

Concerning the total figures, it is understood from the figure 1 that Japanese authors take the lead with 639 boosters, which is followed by Anglophonic authors, 594. Turkish authors bring up the rear with 511 boosters in total. On the other hand, regarding categorical boosters in total, it is seen that adverbial boosters with 515 in total lead the way, which is followed by adjectival boosters, verbal boosters and modal boosters, respectively; 461, 444, and 324. Furthermore, Anglophonic and Japanese authors employed adverbial boosters in their RAs at most, meanwhile Turkish authors had a tendency of using verbal boosters.

\subsection{Modal Auxiliaries}

A one-way ANOVA was utilized to investigate the effect of author nationality (Anglophonic, Japanese, and Turkish) on modal auxiliary boosters. The findings yielded a statistically significant difference among three groups of authors $(F(2,57)=4,254, p<.05)$ regarding modal auxiliary boosters. Therefore, to determine where the difference is, post hoc test was run. According to post hoc results, only one pair was found to have a statistically significant difference with respect to modal auxiliary boosters: Japanese authors $(M=4.80, S D=.616)$ and Turkish authors $(M=5.45, S D=.686)$ at $p<.01$ level. However, other groups, namely Japanese-Anglophonic and Anglophonic-Turkish, do not differ significantly when modal auxiliary boosters are taken into account.

Specifically to provide explanation, Anglophonic authors used 'need to' 40 times in their texts while only 9 times 'have/has to'. So, the use of 'need to' made up almost a third of all modal boosters. The first three in the rank are consisted of 'need to', 'will' and 'must', respectively; 40, 30, and 29 (for detail see Appendix B). The results show a difference between Anglophonic and Japanese authors in terms of modal booster preferences. Japanese authors place 'will' to the top rank with 38 times, which is followed by 'need to' 30 times and 'must' 20 times. Different from Anglophonic authors, Japanese authors used 'be to+infinitive' only 3 times, which placed them in the rank of least preferred modal boosters (for detail see Appendix C). Consonant with Japanese authors, Turkish authors included 'will' 44 times in their RAs. It is followed by 'have/has to' and 'must'; 24 and 23 times (for detail see Appendix D). Again similar to Japanese authors, Turkish authors employed 'be to+infinitive' boosting devices only 2 times, which is the minimum figure for all author groups. Briefly, it can be said that while Japanese and Turkish authors have a tendency of not using 'be to+infinitive' in their writings, Anglophonic authors avoid using 'have/has to', which are the boosters preferred highly by Turkish authors.

\subsection{Epistemic Lexical Verbs}

Germane to the effect of author nationality on epistemic verbs functioning as boosters, the results did not show a statistically significant difference among three groups of authors $(F(2,57)=1,844, p>.05)$ regarding epistemic verbs functioning as boosters. So, it can be concluded that there is not a statistically significant relationship between authors in terms of booster using.

Statistical test results informed us about the similarity among all groups in terms of using epistemic lexical verbs. Although there does not exist a statistically significant difference among the authors, their preference and frequency of verbal boosters changed. Regarding Anglophonic authors, the verb 'show' made up almost half of the verbal boosters with 85 times. Then, 'find' and 'establish' verbal boosters come; respectively 20 and 16 . The verbal boosters 'guarantee' and 'essentialise' come at the most back with a number of one. The first rank and distribution in the writings of Japanese authors showed difference. Japanese authors preferred to use 'find' but not 'show' with a figure of 41. 'find' is followed by 'show' 39 times and 'demonstrate' 35 times. Different from Anglophonic authors, Japanese author did not use the verb 'essentialise', and used 'guarantee' three times, which did not make it the least. Three verbal boosters are at the very last with one time usage, they are: enhance, ascertain, and assure. Again the verb 'show' comes forward as the most used verbal boosters in the RAs of Turkish authors. It was used 55 times, which made up almost a third of all epistemic lexical verbs. 'show' is followed by 'find' 50 times, and 'determine' 21 times. The least used two verbal boosters are 'prove' and 'assure'; both two times. The result put forth that while Anglophonic and Turkish authors used the verbal booster 'show' at most, Japanese authors used 'find'.

\subsection{Epistemic Adjectives}

Statistical tests pertaining to epistemic adjectival boosters and author groups yielded a statistically significant difference among three groups of authors $(F(2,57)=17,422, p<.001)$ regarding epistemic adjective boosters. Therefore, to determine where the difference is, post hoc test was run. According to post hoc results, two pairs were found to have a statistically significant difference with respect to epistemic adjective boosters: Japanese authors $(M=10, S D=.00)$ and Turkish authors $(M=6.60, S D=3.515)$ at $p<.001$ level; and Japanese and 
Anglophonic $(M=6.45, S D=.1 .234)$ at $p<.001$ level. However, no statistically significant difference was found between Anglophonic and Turkish authors in terms of using epistemic adjective boosters.

Epistemic adjectives are composed of a wide range of vocabularies when compared to modal and verbal boosters. As seen in the appendices 2, 3 and 4, the adjective '(un)clear' is the most used one by Anglophonic authors. It was used 16 times, after 'extensive' 12 times and 'reliable and consistent' come with each nine times. The least used adjectival boosters, with one time each, are '(in)conclusive, firm, genuine, inevitable, noticeable, secure, sizeable, superior, and sure'. With Japanese authors, the results change greatly. Japanese authors preferred to use the adjectival booster of 'successful' with 50 times, which makes up a fourth of all adjectival boosters. It is followed by '(un)clear' 36 times and 'essential' 16 times. So, it is obvious that Anglophonic and Japanese authors did not match with any of the first three ranks but with '(un)clear'. The least ones with only once usage are 'comprehensive, genuine, indispensible, inevitable, outstanding, radical, reliable, remarkable, undeniable, and certain', some of which are in tune with Anglophonic authors'. The first three rank of Turkish authors regarding adjectival boosters are 'successful, great, and crucial', respectively; 23, 19 and 12. 'considerable', 'remarkable' and 'evident' adjectival boosters were the least used ones with one time each, which completely differ from Anglophonic and Japanese authors' except of 'remarkable'.

\subsection{Epistemic adverbs}

The effect of author nationality on epistemic adverb boosters was investigated and the findings provided a statistically significant difference among three groups of authors $(F(2,57)=33,131, p<.001)$ regarding epistemic adverb boosters. To determine where the difference is, post hoc test was run. According to post hoc results, two pairs were found to have a statistically significant difference with respect to epistemic adjective boosters: Japanese authors $(M=10, S D=.00)$ and Turkish authors $(M=6.30, S D=2.203)$ at $p<.001$ level; and Anglophonic $(M=9.45, S D=1.538)$ and Turkish at $p<.001$ level. However, no statistically significant difference was discovered between Anglophonic and Japanese authors in terms of using epistemic adverb boosters

When the analysis results taken into consideration, it is seen that all the groups have some common epistemic adverbial boosters. To expand on, the most used adverbial boosters in the RAs of Anglophonic authors are 'highly, particularly, and especially', respectively; 23, 21, 20. Despite the fact that adverbial booster 'highly' is at the first rank, the others are very close to it in frequency. On the other hand, there existed a high many of adverbial boosters which were used only once. They are: comprehensively, forcefully, fundamentally, powerfully, prominently, radically, great, notably, truly and uniquely. As for Japanese authors, 'especially, (un)clearly, and indeed are the most used ones, respectively 30,23, and 20. The least used adverbial boosters of Japanese authors are 'definitely, essentially, strikingly, uniquely, and truly. The results of Turkish authors are similar to Japanese authors'. Turkish author used 'especially' 20 times and placed it to the first rank, then '(un)clearly', 19 time, and 'particularly', 13 times, come after. 'apparently, obviously, consistently, constantly, fully, indeed, in fact, necessarily and truly' are the least used adverbial boosters with only one use. When examined overall, it seems that the epistemic adverb 'especially' existed as one of the most used adverbial boosters in all author groups. Another similarity exists between Japanese and Turkish authors in terms of frequency of (un)clearly, which both author groups placed it in their RAs as one of the most used ones.

\subsection{Booster Word Variety Frequency}

Hitherto, total booster frequency, categorical booster frequency, and most and least used boosters for each author group were provided. Under that subtitle, lexical booster word frequency are shown. For example, the question of 'how many kinds of booster words does each group include?' is sought to answer. The table below provides us a general picture.

Table 2. Booster word variety frequency table

\begin{tabular}{lllll}
\hline Boosting Type & Anglophonic & Japanese & Turkish & Total \\
\hline Epis. Modality Verbs & 5 & 5 & 5 & $\mathbf{1 5}$ \\
Epis. Verbs & 11 & 12 & 8 & $\mathbf{3 1}$ \\
Epis. Adjectives & 31 & $\underline{34}$ & 23 & $\mathbf{8 8}$ \\
Epis. Adverbs & $\underline{33}$ & 30 & $\underline{24}$ & $\mathbf{8 7}$ \\
Total & $\mathbf{8 0}$ & $\mathbf{8 1}$ & $\mathbf{6 0}$ & $\mathbf{2 2 1}$ \\
\hline
\end{tabular}

As seen from the table 2, all author groups included five different type of modal boosters in their RAs. In total, there existed 15 modality verb functioning as boosters (they can overlap across author groups). So, it is certain 
that the least booster word variety is with modality verb boosters (for detail see appendices 2, 3, and 4). The verbal boosters, which are at the second rank in variety, show difference at a small scale. While Japanese authors used twelve kinds of verbal boosters in their RAs, the figure was eleven for Anglophonic authors and eight for Turkish authors. Therefore, in their RAs, Turkish authors are those who used the least kinds of verbs functioning as boosters. By keeping the overlapping possibility of the verbal boosters used in each group of authors in mind, we may say that 31 verbal boosters in total were included in the RAs of all three groups, which placed it penultimate. As regards adjectival boosters, it is, again, seen in the table that Japanese authors are those who included the most kinds of adjectival boosters in their RAs. Japanese authors used 34 kinds of adjectival boosters whereas Anglophonic writers 33 kinds and Turkish authors 24. A similar result as in verbal boosters comes forward: While Japanese are at the first rank in adjectival booster variety, Turkish authors are at the last rank. The last category of boosting was adverbial boosters. Here, Japanese authors leave the first rank to Anglophonic authors; 30 to 33. So, Anglophonic authors contained adverbial lexical boosters more than other two groups. Again, Turkish authors are those who are at the last rank in the number of adverbial booster variety; 24 . To talk about totality, Japanese authors used 81 kinds of boosters, which was followed by Anglophonic authors with a minus; 80. However, Turkish authors were at the very rear of both Japanese and Anglophonic authors in terms of lexical boosting variety; 60 .

\section{Discussion}

Through the present study it was aimed to detect similarities and differences among Anglophonic, Japanese and Turkish authors in terms of employing boosting devices in their research articles. To able to reach the research aims, research questions were struggled to be answered through statistical analyses and literature scanning.

$R Q 1$. What are the most common certainty markers that the three groups of writers, namely Turkish, Japanese, and Anglophonic, employed in their writings?

The results showed that all author types proved some similarities as well as differences in terms of their booster preferences. For example, while Anglophonic authors used 'need to', Turkish and Japanese authors used 'will' in the modal auxiliaries category. As regards verbal boosters, we see that Anglophonic authors used 'show' as much three times more than any other verbal boosters. However the case for Japanese authors was not the same. For them, 'show' was the second highest verbal booster after 'find'. Japanese authors employed 'find' functioning as verbal booster in their RAs slightly over than 'show'. In line with Anglophonic authors, Turkish authors used the verbal booster of 'show' at the first rank; it was not as many as in Anglophonic authors' RAs, though. Epistemic adjective '(un)clear', which was considered as an adjectival booster, was employed by Anglophonic authors at most. Yet, that preference was not of choice by Japanese and Turkish authors. They used the adjectival booster of 'successful'. The remarkable thing was that Japanese authors used the adjectival booster of 'successful' two times more than Turkish authors. Concerning the last categorization of boosters in the present study, adverbial booster, a similar picture with adjectival booster comes up. While Anglophonic authors place the adverbial booster of 'highly' onto the first rank, 'especially' was the adverbial booster mostly preferred by Japanese and Turkish authors.

All the differences in frequency between the authors in terms of using boosters prove that nationality can play a role in lexical choice. More, it may be because a nation may have a more considerable inclination over a certain word in expressing the thoughts while another nation focuses on a different specific word, which all the selected words convey similar meanings. Therefore, the way the same information is disposed may be transmitted through different words based on the nationality of the author.

$R Q$ 2. Are there any statistically significant differences between Anglophonic, Japanese and Turkish authors in terms of booster productivity and booster variety?

The research question two was analyzed under four sections: total boosting frequency of authors, categorical boosting frequency of authors, statistical differences, and lexical booster variety. As regards total boosting frequency the results manifested that the highest booster productivity belonged to Japanese authors. They included more boosters than their counterparts. Japanese authors were followed by Anglophonic authors, and then Turkish authors. Although the numerical gap between Japanese and Anglophonic authors was minor, Turkish authors were at a long distance in terms of booster number in total. Therefore, we conclude that Turkish authors do not use certainty markers as much as their Anglophonic and Japanese counterparts. The reason why Turkish authors avoid certainty markers cannot be elicited through explanations of L1 and L2 difference. The boosting frequency results of Japanese authors would also be close to Turkish authors because both are non-native speakers of English were it so. Hence, researchers who try to explain the difference over L1 and L2 difference should keep the result of the present study in mind not to give rise to any possible incorrect 
conclusions. Right here, the importance of culture must be kept in mind because culture has a crucial role in interactional discoursal elements, which boosting is one of. Hyland (2005) states the importance of culture in interactions: "metadiscoursal devices display significant conventional channels of encoding meaning that guide and provide a clearer interpretive situation, representing how authors and audiences interact with each other and involving a culture of communication in their own genre through texts (p. 156)". Some other studies corroborate the results of present study by concluding that native speakers of English use boosting devices more than non-native speakers of English. One example of it belongs to Vassivela (2001) who discovered that Bulgarian English authors employ boosting devices more than native writers of English, especially in discussion parts of their writings, which is a study that did not concur with Hinkel (1997) who found that native speaker and non-native speaker did not differ significantly in the use of discourse particles. Another study, (Yazdani, Sharifi, \& Elyassi, 2014) which is not in line with either Vassivela's or ours but Hinkel's, put forth that American and Persian news articles produced the same assertions and certainty markers with one another, which again proves that the reason is not with L1 and L2 difference but possibly with cultural factors.

The second issue worked out under research question two is the categorical, namely; modal, verbal, adjectival and adverbial, boosting frequency of authors. The findings obviously showed that Anglophonic authors are ahead of Japanese and Turkish authors in modal and verbal boosters whereas Japanese authors are far ahead of Anglophonic and Turkish authors in adjectival and adverbial boosters. It is clearly understood that Turkish author are at the very rear of Anglophonic and Japanese authors in all boosting categorizations. The results are corroborated by the study (Yağız \& Demir, 2014) conducted to investigate hedging tendencies of Turkish authors when compared to native speakers of English. The authors concluded that Turkish authors use tentative language and avoid commitment and boosting when the frequencies of adjectival, adverbial and verbal hedges are taken into consideration.

As aforementioned, the numerical superiority between authors are clear. Further the present study tested whether the difference was statistically significant or not. A statistically significant difference was found between Japanese and Turkish authors in terms of modal boosters; in detail, Japanese authors outnumbered Turkish authors in using modal boosters. On the other hand, non-significant results apropos Anglophonic-Japanese and Anglophonic-Turkish authors were discovered, which means that they were close in using modal boosters in their RAs. No statistically significant difference was found between the groups in terms of verbal boosters. That is to say; all author groups employed verbal boosters at similar numbers in their RAs. As regards adjectival boosters, it was detected that Japanese authors have a high inclination to use them in their writings when compared to Anglophonic and Turkish author. Therefore, there were statistically significant differences between Japanese and Anglophonic; Japanese and Turkish authors. However, no difference was yielded between Anglophonic and Turkish authors which means that they were close to each other from the aspect of using adjectival boosters. The last category, adverbial boosters, showed no difference between Japanese and Anglophonic authors; in large part they were very close to one another. However, Turkish authors were at the very back of both Japanese and Anglophonic authors with respect to adverbial boosters. Therefore statistically significant differences were measure between Japanese-Turkish and Anglophonic-Turkish authors. In general terms, there discovered a proof of the fact that Turkish authors use less persuasive language while writing their RAs when compared to their Japanese and Anglophonic counterparts. Similarly, analysing RA introductions in Polish and English academic journals, Duszak (1994) assured assertive, direct and positive positions of English writers when compared to Polish writers.

The last sub-research of RQ2 was about lexical booster variety of authors. As has been noted in table 2, Japanese authors are at the first rank in lexical booster variety, which is at variance with the study of Kobayashi (2009) who claimed that Japanese EFL learners were at the lack of lexical variations of boosting devices when compared to native speakers of English. Kobayashi had investigated a corpora composed of Japanese written texts, and because the boosting conventions of a writer's first language may be quite different from those used in English (Hinds, 1987), our results may contrast to Kobayashi's. Though Japanese authors used more lexical booster words than Anglophonic authors, the difference was not significant but very slight. In conformity with the findings, we observed lexical redundancy (i.e., low lexical diversity) with Turkish authors, which placed them to the last rank in lexical booster variety. With other say, Turkish authors used less booster words than Japanese and Anglophonic authors.

The linguistics literature provides with some evidences that non-native speakers of English have a tendency over high frequency words than low frequency word. That is because as proven by some early studies that high-frequency words are remembered faster than low-frequency words (see Cattell, 1886), and produced more quickly than low-frequency words (see Oldfield \& Wingfield, 1965). However, that end up with a decrease in 
non-native writers' lexical diversity as well as productivity as seen in the present study apropos Turkish authors. What is conspicuous is that Japanese authors are non-native speakers of English, though they have a high lexical variety degree. Some studies in Linguistics indicate that productivity, in relation to lexical variety, degree in productions of speakers is not only a matter of personality but is also a result affected by linguistic and cultural conventions (Lehtonen \& Sajavaara, 1985). Lexical diversity was studied under many guises in association with lexical productivity, and through them we know that lexical diversity, in both oral speech and writing, shows diversifications based on age, L2 proficiency, L1-L2 proximity, and L1 background (Laufer, 1994), multiple cognitive, stylistic, situational and textual constraints (Dewaele, 1993), and FL or L2 learning contexts (Meare, Lightbrown, \& Halter, 1997). Therefore, to explain linguistically there are a lot of conventions that might affect the high lexical variety of Japanese author when compared to Turkish authors. The findings of the present study echo McCrostie's study (McCrostie, 2005) who compared Japanese academic writers with Anglophonic writers in terms of word frequency. He found that no statistically significant difference exist between Anglophonic and Japanese academic writers from word frequency aspect.

\section{$R Q 3$. How can the results be explained by taking the cultural factors into consideration?}

It is possible authorial stance change from a community to another. While some prefer to be more concise, direct and certain, the others may prefer to be indirect and tentative. A study conducted by Hinkel (1997) discovered that eastern communities such as; Chinese, Korean, Japanese, and Indonesian, mostly appears vague and indirect when compared to native speakers of American English while we found that the case is not as in Hinkel's regarding Japanese authors. On contrary to the general belief that eastern communities avoid assertive statements, the present study found that Japanese authors are not in that circle. That could be because other researches studied hedging but not boosting devices. It is possible for an author to be both assertive and tentative in his/her research writings. Summarily, our research did not prove the common belief regarding Japanese authors. As regards the importance of culture on using more boosters, hence be more assertive, Thomas (1984), in his research on cross-cultural discourse, argues over-assertive talking reasons of non-native speakers of English, and links one of the reasons to pragmatic style and cultural background.

The results provided some insight germane to assertive style of Anglophonic authors. The assertive discourse of Anglophonic writers may partly stem from their confidence as being native speakers of English; the language of the RAs because the proficiency in a given language has an effect of certainty on discourses of producers. Boenisch (2008) accentuates the affiliation between proficiency of language and assertiveness in discourses. Therefore, the assertiveness of Anglophonic authors may not be because they culturally have a style of assertive writing but because they are competent in language, hence feel more assured while expressing their thoughts or making their claims. Different from Boenisch, Wu and Rubin (2000) associated differences of writing features with certain cultural writing conventions; though they, like Boenisch, drew attention to the relation between assertive discourse of essays and writers' linguistic confidence. For them, linguistic insecurity might mitigate the statements.

It is a well-known fact that Turkey is under the influence of west ranging from lifestyle to English spreading. However metadiscoursal features of a community do not change easily at all. For example, Uysal (2012) found that Turkish essays include assertive markers and overstatement in large numbers while in the present study we discovered that essays written in English by Turkish authors do not include boosters as many as Anglophonic authors. High assertive markers in Turkish written essays and low assertive markers in English written essays, as has been noted before, may be concerning with linguistic insecurity. Therefore, that Turkish authors employ less assertive markers in the present study cannot be a certain base to able to claim that Turkish authors are culturally less assertive than their Anglophonic and Japanese counterparts. Through the present study we discovered that cultural effect on boosting is only one part in variations, hence the issue of boosting should be thought in a multidimensional way.

\section{Conclusion}

To able to detect authorial stance, the present study investigated the similarities and differences of three types of authors, Anglophonic, Japanese, and Turkish in terms of using boosting devices. Overall, the results did not give any differences between Anglophonic and Japanese authors, but Turkish-Anglophonic and Turkish-Japanese. Concisely, Turkish authors did not use as many boosters as their Anglophonic and Japanese counterparts. However, together with study results, it is almost impossible to attribute to a nation with a certain type of discourse way. More precisely, it will be too assertive to claim that Anglophonic and Japanese authors are more direct in their RAs and are committed to their stance when compared to Turkish authors. The results of the present study put forth that Japanese and Anglophonic authors use boosting devices at similar scale, though there 
are categorical differences, while Turkish authors' discoursal styles include to be more tentative and less assertive. Anglophonic authors use an assertive language in their writings but we are still not convinced whether it is because they culturally have a style of assertive writing or they are competent in language; because some studies in the literature establish a connection between proficiency in language and assertive writing. Furthermore, it will be too assertive to generalize the results of present study to all other discursive areas of the authors. Possibly, there can be some cross-linguistic or cross-disciplinary differences. The present study gleaned a corpora of ELT RAs to study, which means that the results can be different in other scientific fields. To state profoundly, the results regarding boosting can change if you change the corpora that the data was collected from. What is the claim to be said specifically is that the corpora of ELT did not show any difference between Japanese and Anglophonic authors, and placed Turkish authors to the last rank in using boosters. However, the results may be different if a researcher decide to study on fields other than ELT, or if a researcher conduct a cross-disciplinary research on boosting. Moreover, Turkish authors may be more assertive in L1 than in L2. The situation is the same for Japanese authors. Anglophonic authors were thought as a whole nation in the present study yet there could be some specific personality and characteristic differences between English speaking countries. Therefore, it could be gained more exact results in regard to Anglophonic authors if the corpora gleaned for Anglophonic authors are composed of a certain English speaking nation (i.e. only from U.S.A, UK, or New Zealand etc.). Boosting is an issue gaining importance in the last decades, especially for a better academic writing and to have a persuasive language to readers. Therefore, further studies keeping all these additions and handicaps in consideration may add to the literature in terms of discovering authorial stances of Anglophonic, Japanese and Turkish authors.

\section{References}

Alward, A., Mooi, C., \& Bidin, S. (2012). Hedges and Boosters in the Yemeni EFL Undergraduates' Persuasive Essay: An Empirical Study. The Internet Journal of Language, Culture and Society, 34, 1-12.

Aull, L., \& Lancester, Z. (2014). Linguistic Markers of Stance in Early and Advanced Academic Writing: A Corpus-based Comparison. Written Communication, 31(2), 151-183. http://dx.doi.org/10.1177/0741088314527055

Austin, J. (1962). How to do things with words. Oxford: Oxford University Press.

Boenisch, J. B. (2008). Negotiable Acceptability: Reflections on the Interactions between Language Professionals in Europe and NNS 1 Scientists Wishing to Publish in English. Current Issues in Language Planning, 7(1), 31-43. http://dx.doi.org/10.2167/cilp086.0

Cattell, J. (1886). The time it takes to see and name. Mind, 63-65. http://dx.doi.org/10.1093/mind/os-XI.41.63

Chen, Z. (2012). Expression of Epistemic Stance in EFL Chinese University Students' Writings. English Language Teaching, 5(10), 173-179. http://dx.doi.org/10.5539/elt.v5n10p173

Cmejrkova, S. (1996). Academic writing in Czech and English. In E. Ventola, \& A. Mauranen, Academic writing. Intercultural and textual issues (pp. 137-152). Amsterdam/Philadelphia: John Benjamins. http://dx.doi.org/10.1075/pbns.41.11cme

Crompton, P. (1997). Hedging in Academic Writing: Some Theoretical Problems. English for Specific Purposes, 16, 271-287. http://dx.doi.org/10.1016/S0889-4906(97)00007-0

Dewaele, J.-M. (1993). Extraversion et richesse lexicale dans deux styles d'interlangue française. ITL Review of Applied Linguistics, 100, 87-105.

Dobakhti, L. (2013). Expressing Certainty in Discussion Sections of Qualitative and Quantitative Research Articles. Pan-Pacific Association of Applied Linguistics, 17(1), 57-77.

Duszak, A. (1994). Academic discourse and intellectual styles. Journal of Pragmatics, 21, 291-313. http://dx.doi.org/10.1016/0378-2166(94)90003-5

Gillaerts, P., \& Velde, F. V. (2010). Interactional metadiscourse in research article abstracts. Journal of English for Academic Purposes, 9, 128-139. http://dx.doi.org/10.1016/j.jeap.2010.02.004

Hinds, J. (1987). Reader versus writer accountability: A new typology. In U. Connor \& R. Kaplan (Eds.), Writing across languages: Analysis of L2 text (pp. 141-152). Reading, MA: Addison-Wesley.

Hinkel, E. (1997). Indirectness in L1 and L2 academic writing. Journal of Pragmatics, 27, 361-386. http://dx.doi.org/10.1016/S0378-2166(96)00040-9 
Holmes, J. (1984). Modifying illocutionary force. Journal of Pragmatics, 8, 345-365. http://dx.doi.org/10.1016/0378-2166(84)90028-6

Holmes, J. (1990). HEDGES AND BOOSTERS IN WOMEN'S AND MEN'S SPEECH. Language \& Communication, 3, 185-205. http://dx.doi.org/10.1016/0271-5309(90)90002-S

Hu, G., \& Cao, F. A.-a.-m. (2011). Hedging and boosting in abstracts of applied linguistics articles. Journal of Pragmatics, 43, 2795-2809. http://dx.doi.org/10.1016/j.pragma.2011.04.007

Hyland, K. (1998). Boosting, hedging and the negotiation of academic knowledge. Text, 18, 349-382. http://dx.doi.org/10.1515/text.1.1998.18.3.349

Hyland, K. (1998b). Exploring corporate rhetoric: Metadiscourse in the CEO's letter. The Journal of Business Communication, 35, 224-245. http://dx.doi.org/10.1177/002194369803500203

Hyland, K. (2000). Hedges, Boosters and lexical invisibility: noticing modifiers in academic texts. Language Awareness, 9(4), 179-197. http://dx.doi.org/10.1080/09658410008667145

Hyland, K. (2005). Metadiscourse: Exploring interaction in writing. Londond: Continuum.

Hyland, K. (2005). Stance and engagement: a model of interaction in academic discourse. Discourse Studies , 7(2), 173-192. http://dx.doi.org/10.1177/1461445605050365

Kaplan, R. (1976). Cultural thought patterns in intercultural education. Language learning, 16, 1-20. http://dx.doi.org/10.1111/j.1467-1770.1966.tb00804.x

Khedri, M., Ebrahimi, J., \& Heng, S. (2013). Interactional Metadiscourse Markers in Academic Research Article Result and Discussion Sections. The Southeast Asian Journal of English Language Studies, 19(1), 65-74.

Kim, C. H., \& Suh, H. W. (2014). Epistemic Rhetorical Stance: Hedges and Boosters in L1 and L2 Students' English Writings. The Linguistic Association of Korea Journal, 22(2), 61-93. http://dx.doi.org/10.17154/kjal.2014.03.30.1.61

Kobayashi, Y. (2009). Extracting characteristics of English essays written by Japanese EFL learners. Proceedings of Jinmonkon Symposium Series of Information Processing Society of Japan (pp. 261-268). Osaka: Information Processing Society.

Kondowe, W. (2014). HEDGING AND BOOSTING AS INTERACTIONAL METADISCOURSE IN LITERATURE DOCTORAL DISSERTATION ABSTRACTS. International Journal of Language Learning and Applied Linguistics World, 214-221.

Laufer, B. (1994). The lexical profile of second language writing: Does it change over time? RELC Journal, 25, 21-33. http://dx.doi.org/10.1177/003368829402500202

Lehtonen, J., \& Sajavaara, K. (1985). The silent Finn. In D. Tannen, \& M. Saville-Troike (Eds.), Perspective on Silence (pp. 193-201). Norwood, NJ: Ablex.

Lewin, B. (2005). Hedging: an exploratory study of authors' and readers' identification of 'toning down' in scientific texts. Journal of English for Academic Purposes, 4, 163-178. http://dx.doi.org/10.1016/j.jeap.2004.08.001

McCrostie, J. (2005). A Further Investigation of Word Frequency Intuitions. East Asian Learner, 2(1), 26-36.

Meare, P., Lightbrown, P., \& Halter, R. (1997). Classrooms as lexical environments. Language Teaching Research, 1, 2847. http://dx.doi.org/10.1177/136216889700100103

Nivales, M. (2011). Hedging in College Research Papers: Implications for Language Instruction. Asian EFL Journal, 35-45.

Oldfield, R. C. (1965). Response latencies in naming objects. Quarterly Journal of Experimental Psychology, 272-281. http://dx.doi.org/10.1080/17470216508416445

Peacock, M. (2006). A cross-disciplinary comparison of boosting in research articles. Corpora, 1(1), 61-84. http://dx.doi.org/10.3366/cor.2006.1.1.61

Salek, M. (2014). A Diagram of Interactive and Interactional Markers in Different Parts of English Research Articles. Journal of Language Sciences \& Linguistics, 2(3), 55-66.

Searle, J. (1969). Speech acts. An essay in the philosophy of language. Cambridge: Cambridge University Press. http://dx.doi.org/10.1017/CBO9781139173438 
Shabani, E., \& Meraji, S. (2010). Preference Consequentialism: An Ethical Proposal to Resolve the Writing Error Correction Debate in EFL Classroom. International Journal of Language Studies, 69-88.

Thomas, J. (1984). Cross-Cultural Discourse as 'Unequal Encounter': Towards a Pragmatic Analysis. Applied Linguistics, 5(3), 226-235. http://dx.doi.org/10.1093/applin/5.3.226

Uysal, H. (2014). A Cross-cultural Study of Indirectness and Hedging in the Conference Proposals of English NS and NNS Scholars. Occupying Niches: Interculturality, Cross-culturality and Aculturality in Academic Research, 179-195. http://dx.doi.org/10.1007/978-3-319-02526-1_12

Uysal, H. H. (2012). Argumentation across L1 and L2 Writing: Exploring Cultural Influences and Transfer Issues. VIAL-Vigo International Journal of Applied Linguistics, 9, 133-159.

Vassileva, I. (2001). Commitment and detachment in English and Bulgarian academic writing. English for Specifc Purposes, 83-102. http://dx.doi.org/10.1016/S0889-4906(99)00029-0

Vázquez, I., \& Giner, D. (2009). Writing with Conviction: The Use of Boosters in Modelling Persuasion in Academic Discourses. Revista Alicantina de Estudios Ingleses, 22, 219-237.

Wee, L. (2004). Extreme communicative acts' and the boosting of illocutionary force. Journal of Pragmatics, 36, 2161-2178. http://dx.doi.org/10.1016/j.pragma.2004.01.001

Wu, S.-Y., \& Rubin, D. (2000). Evaluating the Impact of Collectivism and Individualism on Argumentative Writing by Chinese and North American College Students. Research in the Teaching of English, 35(2), 148-178.

Yağız, O., \& Demir, C. (2014). Hedging strategies in academic discourse: A comparative analysis of Turkish writers and native writers of English. 14th International Language, Literature and Stylistics Symposium (pp. 260-268). İzmir: Procedia - Social and Behavioral Sciences.

Yang, Y. (2013). Exploring linguistic and cultural variations in the use of hedges in English and Chinese scientific discourse. Journal of Pragmatics, 50, 23-36. http://dx.doi.org/10.1016/j.pragma.2013.01.008

Yazdani, S., Sharifi, S., \& Elyassi, M. (2014). Interactional Metadiscourse in English and Persian News Articles about 9/11. Theory and Practice in Language Studies, 4(2), 428-434. http://dx.doi.org/10.4304/tpls.4.2.428-434 


\section{Appendix A}

Boosting List

\begin{tabular}{|c|c|c|c|c|}
\hline Modal Boosters & Verbal Boosters & Adjectival Boosters & Adverbial Boosters & \\
\hline Be to+infinitive & Ascertain & Absolute & Absolutely & Safely \\
\hline Have/has to & Assure & Apparent & Always & Securely \\
\hline Must & Conclude & Categorical & Apparently & Surely \\
\hline Need to & Confirm & Certain & Assuredly & Strikingly \\
\hline \multirow[t]{61}{*}{ Will } & Corroborate & (un)clear & Categorically & Successfully \\
\hline & Convince & Compelling & Certainly & Thoroughly \\
\hline & Demonstrate & Comprehensive & (un)clearly & Totally \\
\hline & Determine & Conclusive & Completely & Truly \\
\hline & Deserve & Considerable & Comprehensively & Unambiguously \\
\hline & Enhance & Consistent & Conclusively & Unarguably \\
\hline & Essentialise & Conspicuous & Considerably & Undeniably \\
\hline & Establish & Constant & Consistently & Undoubtedly \\
\hline & Find & Convincing & Conspicuously & Unequivocal \\
\hline & Guarantee & Credible & Constantly & Uniquely \\
\hline & Justify & Crucial & Convincingly & Unlimited \\
\hline & Perfect & Decisive & Credibly & Unmistakably \\
\hline & Prove & Definite & Crucially & Unquestionably \\
\hline & Secure & Distinct & Decisively & Vastly \\
\hline & Show & Essential & Definitely & Vitally \\
\hline & Substantiate & Evident & Deservedly & \\
\hline & Uphold & Exceptional & Distinctly & \\
\hline & & Firm & Doubtless & \\
\hline & & Forceful & Entirely & \\
\hline & & Fundamental & Especially & \\
\hline & & Genuine & Essentially & \\
\hline & & Great & Evidently & \\
\hline & & Impossible & Exceptionally & \\
\hline & & Impressive & Exhaustively & \\
\hline & & Inconvertible & Extensively & \\
\hline & & Indispensible & Extremely & \\
\hline & & Inevitable & Exceptional & \\
\hline & & Manifest & Firm & \\
\hline & & Marked & Forcefully & \\
\hline & & Noteworthy & Fully & \\
\hline & & Noticeable & Fundamentally & \\
\hline & & Obvious & Genuinely & \\
\hline & & Outstanding & Great & \\
\hline & & Perfect & Impossibly & \\
\hline & & Persuasive & Highly & \\
\hline & & Plain & Impressively & \\
\hline & & Powerful & Inconvertibly & \\
\hline & & Profound & Indeed & \\
\hline & & Prominent & Indispensably & \\
\hline & & Radical & Inevitably & \\
\hline & & Reliable & In fact & \\
\hline & & Remarkable & Markedly & \\
\hline & & Rigorous & Necessarily & \\
\hline & & Safe & Never & \\
\hline & & Self-evident & No doubt & \\
\hline & & Sizeable & notably & \\
\hline & & Striking & Noticeably & \\
\hline & & Successful & Obviously & \\
\hline & & Superior & Particularly & \\
\hline & & Sure & Perfectly & \\
\hline & & Thorough & Persuasively & \\
\hline & & Unambiguous & Plainly & \\
\hline & & Undeniable & Precisely & \\
\hline & & Unequivocal & Profoundly & \\
\hline & & Unique & Prominent & \\
\hline & & Unmistakable & Quite & \\
\hline & & Unprecedented & Radically & \\
\hline & & Unquestionable & Really & \\
\hline & & Vast & Reliably & \\
\hline & & Vital & Remarkably & \\
\hline & & Well-know & Rigorously & \\
\hline
\end{tabular}




\section{Appendix B}

Boosting List that Anglophonic Authors Included in Their Research Articles

\begin{tabular}{|c|c|c|c|c|c|c|c|}
\hline Modal auxiliaries & N. & Epis. Lexical verbs & N. & Epis. adjectives & N. & Epis. Adverbs & N. \\
\hline Be to + infinitive & 11 & Ascertain & 3 & Absolute & 3 & Always & 6 \\
\hline Have/has to & 9 & Confirm & 4 & Apparent & 6 & Certainly & 5 \\
\hline Must & 29 & Demonstrate & 10 & (un) clear & 16 & (un) clearly & 10 \\
\hline Need to & 40 & Deserve & 2 & Comprehensive & 5 & Completely & 2 \\
\hline \multirow[t]{28}{*}{ Will (not) } & 30 & Determine & 8 & (in) conclusive & 1 & Comprehensively & 1 \\
\hline & & Essentialise & 1 & Considerable & 6 & Consistently & 7 \\
\hline & & Establish & 16 & Consistent & 9 & Constantly & 2 \\
\hline & & Find & 20 & Constant & 8 & Definitely & 2 \\
\hline & & Guarantee & 1 & Crucial & 4 & Entirely & 2 \\
\hline & & Prove & 6 & Essential & 7 & Especially & 20 \\
\hline & & Show & 85 & Evident & 7 & Essentially & 3 \\
\hline & & & & Extensive & 12 & Extensively & 4 \\
\hline & & & & Firm & 1 & Extremely & 2 \\
\hline & & & & Fundamental & 3 & Forcefully & 1 \\
\hline & & & & Genuine & 1 & Fully & 11 \\
\hline & & & & Great & 3 & Fundamentally & 1 \\
\hline & & & & Inevitable & 1 & Great & 1 \\
\hline & & & & Noteworthy & 2 & Highly & 23 \\
\hline & & & & Noticeable & 1 & Indeed & 13 \\
\hline & & & & Obvious & 2 & In fact & 11 \\
\hline & & & & Powerful & 6 & Necessarily & 6 \\
\hline & & & & Reliable & 9 & Never & 7 \\
\hline & & & & Rigorous & 2 & Notably & 1 \\
\hline & & & & Secure & 1 & Particularly & 21 \\
\hline & & & & Sizable & 1 & Powerfully & 1 \\
\hline & & & & Striking & 2 & Prominently & 1 \\
\hline & & & & Successful & 6 & Quite & 12 \\
\hline & & & & Superior & 1 & Radically & 1 \\
\hline & & & & Sure & 1 & Successfully & 7 \\
\hline & & & & Vital & 2 & Truly & 1 \\
\hline & & & & & & Undoubtedly & 3 \\
\hline & & & & & & Uniquely & 1 \\
\hline Total Frequency & 119 & & 157 & & 129 & & 189 \\
\hline
\end{tabular}

* The bold words represent for the highest frequency words. 


\section{Appendix C}

Boosting List that Japanese Authors Included in Their Research Articles

\begin{tabular}{|c|c|c|c|c|c|c|c|}
\hline Modal auxiliaries & N. & Epis. lexical verbs & N. & Epis. adjective & N. & Epis. adverb & N. \\
\hline Be to + infinitive & 3 & Ascertain & 1 & Absolute & 2 & Always & 5 \\
\hline Have/has to & 5 & Assure & 1 & Apparent & 2 & Apparently & 6 \\
\hline Must & 20 & Confirm & 8 & Certain & 1 & Certainly & 3 \\
\hline Need to & 30 & Conclude & 5 & (un) clear & 36 & (un) clearly & 23 \\
\hline \multirow[t]{30}{*}{ Will (not) } & 38 & Corroborate & 4 & Comprehensive & 1 & Completely & 2 \\
\hline & & Demonstrate & 35 & Considerable & 4 & Consistently & 5 \\
\hline & & Determine & 4 & Consistent & 2 & Constantly & 4 \\
\hline & & Enhance & 1 & Constant & 2 & Definitely & 1 \\
\hline & & Find & 41 & Crucial & 10 & Entirely & 6 \\
\hline & & Guarantee & 3 & Essential & 16 & Especially & 30 \\
\hline & & Prove & 2 & Evident & 8 & Essentially & 1 \\
\hline & & Show & 39 & Fundamental & 4 & Extremely & 5 \\
\hline & & & & Genuine & 1 & Firmly & 2 \\
\hline & & & & Great & 7 & Fully & 6 \\
\hline & & & & Impossible & 5 & Highly & 8 \\
\hline & & & & Indispensible & 1 & Indeed & 20 \\
\hline & & & & Inevitable & 1 & Inevitably & 3 \\
\hline & & & & Manifest & 2 & In fact & 10 \\
\hline & & & & Noticeable & 8 & Necessarily & 3 \\
\hline & & & & Obvious & 2 & Never & 5 \\
\hline & & & & Outstanding & 1 & Obviously & 2 \\
\hline & & & & Powerful & 2 & Particularly & 13 \\
\hline & & & & Prominent & 6 & Perfectly & 2 \\
\hline & & & & Radical & 1 & Quite & 12 \\
\hline & & & & Reliable & 1 & Really & 5 \\
\hline & & & & Remarkable & 1 & Strikingly & 1 \\
\hline & & & & Secure & 2 & Successfully & 13 \\
\hline & & & & Striking & 2 & Truly & 1 \\
\hline & & & & Successful & 50 & Uniquely & 1 \\
\hline & & & & Sure & 3 & Vastly & 2 \\
\hline & & & & Undeniable & 1 & & \\
\hline & & & & Unique & 10 & & \\
\hline & & & & Vast & 2 & & \\
\hline & & & & Vital & 3 & & \\
\hline Total frequency & 96 & & 143 & & 200 & & 200 \\
\hline
\end{tabular}

* The bold words represent for the highest frequency words. 


\section{Appendix D}

Boosting List that Turkish Authors Included in Their Research Articles

\begin{tabular}{|c|c|c|c|c|c|c|c|}
\hline Modal auxiliaries & N. & Epis. lexical verbs & N. & Epis. adjective & N. & Epis. adverb & N. \\
\hline Be to + infinitive & 2 & Assure & 2 & Absolute & 4 & Absolutely & 2 \\
\hline Have/has to & 24 & Confirm & 5 & (un) clear & 9 & Always & 11 \\
\hline Must & 23 & Conclude & 6 & Comprehensive & 4 & Apparently & 1 \\
\hline Need to & 16 & Determine & 21 & Considerable & 1 & (un) clearly & 19 \\
\hline \multirow[t]{19}{*}{ Will (not) } & 44 & Enhance & 3 & Consistent & 5 & Completely & 4 \\
\hline & & Find & 50 & Constant & 2 & Consistently & 1 \\
\hline & & Prove & 2 & Crucial & 12 & Constantly & 1 \\
\hline & & Show & 55 & Essential & 9 & Especially & 20 \\
\hline & & & & Evident & 1 & Extremely & 5 \\
\hline & & & & Great & 19 & Fully & 1 \\
\hline & & & & Impossible & 6 & Highly & 11 \\
\hline & & & & Indispensible & 3 & Indeed & 1 \\
\hline & & & & Inevitable & 5 & Inevitably & 3 \\
\hline & & & & Obvious & 10 & In fact & 1 \\
\hline & & & & Prominent & 2 & Necessarily & 1 \\
\hline & & & & Radical & 2 & Never & 8 \\
\hline & & & & Reliable & 3 & Obviously & 1 \\
\hline & & & & Remarkable & 1 & Particularly & 13 \\
\hline & & & & Successful & 23 & Perfectly & 3 \\
\hline & & & & Sure & 3 & Quite & 7 \\
\hline & & & & Unique & 4 & Really & 6 \\
\hline & & & & Vast & 2 & Successfully & 3 \\
\hline & & & & Vital & 2 & Truly & 1 \\
\hline Total frequency & 109 & & 144 & & 132 & & 126 \\
\hline
\end{tabular}

* The bold words represent for the highest frequency words.

\section{Copyrights}

Copyright for this article is retained by the author(s), with first publication rights granted to the journal.

This is an open-access article distributed under the terms and conditions of the Creative Commons Attribution license (http://creativecommons.org/licenses/by/3.0/). 